\title{
Dynamic recrystallization behavior of AISI 422 stainless steel during hot deformation processes
}

\author{
R. Mohammadi Ahmadabadi ${ }^{1}$, M. Naderi ${ }^{1, *}$, J. Aghazadeh Mohandesi ${ }^{1}$, Jose Maria Cabrera ${ }^{2,3}$ \\ ${ }^{1}$ Department of Mining and Metallurgical Engineering, Amirkabir University of Technology, Tehran, P. O. \\ Box 15875-4413, Iran. \\ ${ }^{2}$ Departamento de Ciencia de los Materiales e Ingenierı'a Metalu' rgica, ETSEIB, Universitat Polite 'cnica \\ de Catalunya, Av. Diagonal 647, 08028 Barcelona, Spain \\ ${ }^{3}$ Fundacio' CTM Centre Tecnologic, Av. Bases de Manresa 1, 08242 Manresa, Spain \\ ( ${ }^{*}$ Corresponding Author. Tel.: +98 21 64542978; Fax: +98 21 64542893, E-mail: mnaderi@aut.ac.ir )
}

\begin{abstract}
Dynamic recrystallization (DRX) behavior of AISI 422 martensitic stainless steel has been investigated at deformation temperatures of $950-1150{ }^{\circ} \mathrm{C}$ and strain rates of $0.01-1 \mathrm{~s}^{-1}$. The critical stress for initiation of DRX was determined based on strain hardening rate dependence to flow stress. The normalized critical stress was estimated as $\sigma_{\mathrm{c}} / \sigma_{\mathrm{P}}=0.84$. In addition, considering the material constants as a function of strain via a third order polynomial fitting, the effect of strain was investigated using an Arrhenius type constitutive equation. Furthermore, in order to examine the competency of the strain-dependent constitutive equations to predict flow stress curves of AISI 422 martensitic stainless steel, two of these constitutive models (Akbari and Ebrahimi models) were investigated. It was found that Akbari et al. constitutive equation can give a more precise estimation of flow stress curves for the alloy of this study.
\end{abstract}

Keywords: AISI 422 stainless steel; Dynamic recrystallization; Stress-Strain curve; Hot deformation; Constitutive equation. 


\section{Introduction}

The AISI 422 martensitic stainless steel is a candidate for high temperature and corrosive environments at service temperature up to $650{ }^{\circ} \mathrm{C}$. This martensitic stainless steel with excellent mechanical properties has been widely used for manufacturing disks, rotors, high temperature bolting and gas turbine blades $[1,2]$. The steel has been developed by correcting its chemical composition in comparison to ÉI802 steel, in order to decrease considerably the amount of $\delta$ ferrite phase. Because of long-term exposure at elevated temperatures, the stability of the microstructures and mechanical properties of the steel is very important [3]. Generally, hot deformation processing is commonly applied for the production of steels with a number of desirable microstructures and mechanical properties. In order to achieve this goal, the forming parameters including deformation temperature, strain per pass, strain rate and etc., must be controlled accurately [4- 6]. During hot deformation processing, dynamic recovery (DRV) or dynamic recrystallization (DRX) can be regarded as the dominant softening mechanisms depending on deformation parameters. The latter mechanisms are of great importance in controlling of the microstructure as well as the flow stress of material. The kinetics of DRV in material with low stacking fault energy, such as the austenite phase in stainless steels, is relatively low and DRX can be initiated at a certain degree of stress accumulation [7,8]. DRX phenomena is acknowledged as an important feature to restore the ductility of the materials which are being work hardened during deformation process [9-11]. The DRX occurred more preferably at higher deformation temperatures and lower strain rates, which in turns causes the grain refinement of the alloy [12-14].

Despite the widespread use of the AISI 422 stainless steel, only a little information on the hot deformation behavior of this steel has been published. Thus, the main objective of the present work is to investigate the effect of deformation temperature and strain rate on the hot deformation behavior of the steel by means of hot compression tests. In this regards, hot compression tests were conducted at strain rates of $0.01,0.1$ and $1 \mathrm{~s}^{-1}$ and temperature range of 950-1150 ${ }^{\circ} \mathrm{C}$. For this purpose, first the effect of hot deformation parameters on the microstructures of the alloy was investigated; second, the critical stress for initiation of DRX was determined according to Najafizadeh and Jonas method [15] and a constitutive equation describing the dependence of the flow stress on the deformation temperature, strain rate and 
strain was derived and finally, two constitutive models were investigated for modeling of flow stress behavior of the stainless steel.

\section{Experimental procedure}

The chemical composition of AISI 422 martensitic stainless steel used in this investigation is presented in Table 1. The optical and SEM micrographs of the hot forged steel indicated a fully martensite structure as shown in Error! Reference source not found.. A Baehr DIL 805 deformation dilatometer was used to perform the hot compression tests. Cylindrical specimens for hot compression tests with $5 \mathrm{~mm}$ in diameter and $10 \mathrm{~mm}$ in height were prepared by an electrical discharge machining (EDM) from hot forged billet according to the ASTM A1033 standard. The hot compression tests were conducted as shown schematically in Fig.2. The specimens were heated to $1200^{\circ} \mathrm{C}$ and held for $5 \mathrm{~min}$ to obtain a homogenous austenitic structure before testing and then were cooled down to the deformation temperature at a cooling rate of 10 ${ }^{\circ} \mathrm{C} / \mathrm{s}$. The specimens were held at the deformation temperature for $20 \mathrm{~s}$ to achieve a uniform temperature and finally subjected to hot compression tests at the temperatures of $950{ }^{\circ} \mathrm{C}, 1000$ ${ }^{\circ} \mathrm{C}, 1050^{\circ} \mathrm{C}, 1100^{\circ} \mathrm{C}$ and $1150^{\circ} \mathrm{C}$ and strain rates of $0.01,0.1$ and $1 \mathrm{~s}^{-1}$. Deformed specimens were quenched instantly to preserve the hot deformation microstructure in order to study the DRX microstructure. The deformed specimens were cut by EDM through longitudinal direction for microstructural investigation. The specimens were polished according to ASTME3 standard. The prior austenite grain boundaries were revealed by an innovative chemical etching solution with the composition of $3 \mathrm{~g} \mathrm{CuCl}_{2}, 4 \mathrm{~g} \mathrm{FeCl}_{3}, 5 \mathrm{ml} \mathrm{HCl}$ and $50 \mathrm{ml} \mathrm{H} 2 \mathrm{O}$. The average grain size and volume fraction of recrystallized structure was estimated using Clemex image analyzer software.

\section{Results and discussion}

\subsection{Effect of deformation conditions on flow stress curves}

Generally, under hot compression experiments, flow stress curves can be classified into two categories: DRV and DRX type. In the DRV curves, flow stress increases with strain in the initial stage of deformation and then reaches a steady state condition as a result of attaining a balance between work hardening and softening rate. In this regards, the dislocations accumulated by deformation process is annihilated by slip and climbing [10]. However, in DRX curves, flow stress initially increases with strain up to a peak, and then decreases continuously to a final 
steady state value. In this way, the drop in flow stress is attributed to nucleation and growth of new-free dislocation grains from plastically deformed matrix. The true stress-true strain curves at different deformation temperatures and strain rates are shown in Fig.3. It is worth mentioning that the flow stress curves are considerably affected by both deformation temperature and strain rate. The flow stress, at constant strain rate, will be decreased when the deformation temperature is increased. At higher deformation temperatures, diffusion of atoms increases causing easier nucleation and mobility of grain boundaries and hence the rate of DRX increases. Therefore, the drop in the flow stress at higher deformation temperature is due to the increase in the rate of restoration mechanisms and the decrease in the work hardening rate. In this regards, the critical strain for initiation of DRX shifts to a lower strain value, since the formation of DRX nuclei become easier at higher deformation temperatures. The rise in flow stress with increasing strain rate can be attributed to the decrease in the rate of restoration processes and increase in work hardening rate. Moreover, the rate of DRV also decreases with increasing strain rates. It has been reported that the formation of DRX nuclei depends on the DRV substructures [15]. Therefore, the critical strain for initiation of DRX increases with increasing of strain rate.

As clearly seen in Fig.3, DRX is the dominant mechanism of most of the present experimental hot compression tests, especially at high temperature and low strain rate. However, when the strain rate increases or the deformation temperature decreases the peak is not clearly obvious. From Fig.3, it can be seen that the dynamic recrystallization have occurred for all deformation temperatures at strain rates of 0.1 and $0.01 \mathrm{~s}^{-1}$. Moreover, with increasing deformation temperature the peak stress shifts to a lower value. For instance, when the deformation temperature increases from $950^{\circ} \mathrm{C}$ to $1150^{\circ} \mathrm{C}$, the peak corresponding to the strain rate of $0.01 \mathrm{~s}^{-1}$ diminishes from $120 \mathrm{MPa}$ to $70 \mathrm{MPa}$. However, the true stress-strain curves at strain rate of $1 \mathrm{~s}^{-1}$ at all deformation temperatures show no stress drops i.e. they are characteristic of dynamic recovery. As shown in Fig.3(a), the flow stresses reach the steady stress value with increasing strain, which indicated that no dynamic recrystallization had taken place at strain rate of $1 \mathrm{~s}^{-1}$.

\subsection{Effect of deformation on the resulted DRX microstructures}

Fig. 4 shows the optical micrographs of AISI 422 MSS before and after deformation, revealing the microstructures corresponding to the central part of the specimens. Fig. 4(a) illustrates the as received and undeformed microstructure. A clear coarse and equiaxed grains with a mean grain size of about $53 \mu \mathrm{m}$ are noticed. Also, the grain size distribution of as received specimen is 
illustrated in Fig. 5. The primary austenite grains were elongated along the deformation direction after compression at $1100^{\circ} \mathrm{C}$ and strain rate of $1 \mathrm{~s}^{-1}$, as shown in Fig. 4(b). Therefore, referring to Fig.3(a), the DRV is the dominating softening mechanism in this deformation condition and no DRX occurred. However, despite the flow stress of the deformed specimen at $1150{ }^{\circ} \mathrm{C}$ and $1 \mathrm{~s}^{-1}$ indicated as DRV processes, approximately 3\% of volume fraction of DRX was observed in the microstructure. Fig. 4(c) shows the microstructure of deformed specimen at $1150{ }^{\circ} \mathrm{C}$ and $0.1 \mathrm{~s}^{-1}$. The new DRX grains nucleated at the primary austenite grain boundaries. The microstructure has a duplex structure consisting of 15\% ASTM 10.0 recrystallized grains and about 85\% ASTM 5.2 unrecrystallized grains. As illustrated in Fig. 4(c), only a small portion of the microstructure has recrystallized dynamically and may be the growth of the grains continues in meta-dynamic condition. The microstructure of the deformed specimen at $1100{ }^{\circ} \mathrm{C}$ and $0.1 \mathrm{~s}^{-1}$ is shown in Fig. 4(d), only a small portion of structure has been refined as a result of DRX. The recrystallized grains have only $5 \%$ of structure with the grain size of about ASTM 11.0.

\subsection{Critical stress for initiation of DRX}

Ryan and McQueen proposed that the critical stress for initiation of DRX can be considered as the inflection point of the strain hardening rate versus stress curve $(\theta-\sigma)$ [17]. In this regard, the method of Najafizadeh and Jonas was proposed by modifying the Poliak and Jonas method to derive such inflection point[15]. According to this simple method, a third-order equation can be fitted to the experimental $\theta-\sigma$ curves from the yield stress to the peak stress according to the following equation:

$\theta=A \sigma^{3}+B \sigma^{2}+C \sigma+D$

Where $A, B, C$, and $D$ are material constants for a given set of deformation conditions. The first derivative of the equation with respect to $\sigma$ can be represented as Eq.[2.

$\frac{d \theta}{d \sigma}=3 A \sigma^{2}+2 B \sigma+C$

In the inflection point of the $\theta-\sigma$ curves the second derivative becomes zero and the critical stress for initiation of DRX can be calculated as follows:

$\frac{d^{2} \theta}{d \sigma^{2}}=0 \rightarrow 6 A+2 B=0 \rightarrow \sigma_{C}=-\frac{B}{3 A}$ 
Fig. 6 shows the first derivative of the work hardening rate versus stress at the deformation temperature of $1150^{\circ} \mathrm{C}$ and strain rate of $0.1 \mathrm{~s}^{-1}$. Therefore, in the Fig. 6 the critical point, indicating the critical stress for initiation of DRX, appears as minimum in the $d \theta / d \sigma-\sigma$ curve. Fig. 7 shows the critical stress for initiation of DRX versus the peak stress at different deformation conditions. The relationship between critical stress and peak stress can almost be expressed as $\sigma_{\mathrm{C}}$ $=0.84 \sigma_{\mathrm{P}}$, which generally is in agreement with other published results $[16,19]$.

\subsection{Constitutive equations}

The constitutive equation of material refers to the relationship between flow stress, deformation temperature and strain rate. The relationship between temperature, strain rate and flow stress can be described by an Arrhenius equation. As discussed in previous sections, deformation temperature and strain rate have great influence on the dynamic recrystallization behavior of 422 MSS. The effects of deformation temperature and strain rate on the hot deformation behavior of the alloy can be represented by the Zener-Holloman parameter $(Z)$ using the following equations $[17,18]$ :

$\mathrm{Z}=\varepsilon \exp \left(\frac{\mathrm{Q}}{\mathrm{RT}}\right)=\mathrm{f}(\sigma)$

$A \sigma^{n_{1}} \cdot \exp \left(\frac{-Q}{R T}\right), \alpha \sigma<0.8$

A. $\exp (\beta \sigma) \exp \left(\frac{-Q}{R T}\right), \alpha \sigma>1.2$

$A[\sinh (\alpha \sigma)]^{n} \cdot \exp \left(\frac{-Q}{R T}\right)$, for all $\sigma$

where, $\mathrm{Z}$ is the Zener-Hollomon parameter, $\varepsilon^{\cdot}$ is strain rate $\left(\mathrm{s}^{-1}\right), \mathrm{T}$ is deformation temperature $(\mathrm{K}), \mathrm{R}$ is the universal gas constant $(8.314 \mathrm{~J} / \mathrm{mol} . \mathrm{K}), \mathrm{Q}$ is the activation energy for dynamic recrystallization $(\mathrm{kJ} / \mathrm{mol}), \sigma$ is the flow stress $(\mathrm{MPa})$ for a given strain and $\mathrm{A}, \mathrm{n}, \mathrm{n}_{1}, \alpha$ and $\beta$ are material constants in which $\alpha=\beta / \mathrm{n}_{1}$.

The power law description of flow stress in Eq. [5] is conventionally used for creep mechanism. On the contrary, the exponential law in Eq. [5] is appropriated for deformation processes in higher strain rates, whereas the hyperbolic sine law can be employed for a wide range of deformation conditions [18].

Flow stress data from the compression tests at various deformation conditions were used to evaluate the material constants for the constitutive equations, where those were determined under 
constant strain. The following are the evaluation procedures of material constants of constitutive equations at a certain strain.

At low and high stress level, the relationship between flow stress and strain rate can be presented as follows:

$\varepsilon^{\cdot}=A \sigma^{n_{1}} \exp \left(\frac{-Q}{R T}\right)=B \sigma^{n_{1}}$

$\varepsilon^{\cdot}=A \exp (\beta \sigma) \exp \left(\frac{-Q}{R T}\right)=C \exp (\beta \sigma)$

where $\mathrm{B}$ and $\mathrm{C}$ are material constants, depending on deformation temperature. The logarithm of both sides of Eqs. [6] and [7] is taken, which gives the following equations, respectively.

$\ln (\sigma)=\frac{1}{n_{1}} \ln \left(\varepsilon^{\cdot}\right)-\frac{1}{n_{1}} \ln (B)$

$\sigma=\frac{1}{\beta} \ln \left(\varepsilon^{\cdot}\right)-\frac{1}{\beta} \ln (C)$

For low and high stress levels, the flow stress values can be given also logarithmic form of Eq.[5] as following equation:

$\ln [\sinh (\alpha \sigma)]=\ln \left(\frac{\varepsilon}{n}\right)+\left(\frac{Q}{n R T}\right)-\ln \left(\frac{A}{n}\right)$

The relationship between flow stress and strain rate can be formulated by substituting the value of the flow stress and corresponding strain rate in Eq. [8] and Eq. [9]. The values of $n_{1}$ and $\beta$ can be obtained from the slope of the lines $\ln \varepsilon^{\circ}-\ln \sigma$ and $\ln \varepsilon^{\circ}-\sigma$ curves, respectively (Fig.8(a) and b). As illustrated in these Figs., the slopes of the lines in different deformation temperatures are approximately the same. The inverse of the mean value of the slopes was taken as the value of $\mathrm{n}_{1}$ and $\beta$ considering the true strain of 0.1 they were calculated to be 9.12 and $0.084 \mathrm{MPa}^{-1}$, respectively. Therefore, the value of $\alpha$ is given as $\alpha=\beta / \mathrm{n}=0.0092$. Also, the value of $\mathrm{n}$ was obtained from the inverse slope of $\ln [\sinh (\alpha \sigma)]$ versus $\ln \varepsilon^{\cdot}($ Fig.8(c)), which was calculated to be 6.86. For a certain strain rate, the activation energy $(\mathrm{Q})$ can be estimated by differentiating Eq. [10] as follows: 


$$
Q=n R \frac{d\{\ln [\sinh (\alpha \sigma)]\}}{d\left(\frac{1}{T}\right)}
$$

The value of Q can be obtained as the average slopes of $\ln [\sinh (\alpha \sigma)]$ versus1/T plots (Fig.8(d)). The average activation energy for different strain rates over temperature range of $950-1150{ }^{\circ} \mathrm{C}$ was calculated as $420 \mathrm{~kJ} / \mathrm{mol}$. In this regards, the activation energy for most of low alloy and micro-alloyed steels is about $270-300 \mathrm{~kJ} / \mathrm{mol}$ [20]. Also, for austenitic stainless steel, such as AISI 304, it is about $410 \mathrm{~kJ} / \mathrm{mol}$ [21]. The alloying element amount in the AISI 422 steel is higher than in low alloy steels but lower than in AISI 304 austenitic stainless steels. Therefore, the activation energy of AISI 422 alloy is obviously higher than that of most low alloy and lower than that of austenitic stainless steel. The Zener-Holloman parameter can be written as following equation:

$Z=\varepsilon^{\cdot} \exp \left(\frac{420000}{R T}\right)$

The value of $A$ at a particular strain could be computed by plotting the correlation between $\ln Z$ versus $\ln [\sinh (\alpha \sigma)]$. As shown in Fig. 9, the value of $A$ at strain of 0.1 was calculated to be $9.24 \times 10^{14}$. By substituting the value of $\alpha, \mathrm{n}, \mathrm{Q}$ and $\mathrm{A}$ as material constants into Eq. [5], the constitutive equation at the true strain of 0.1 can be expressed as following equation:

$\varepsilon^{\cdot}=9.24 \times 10^{14}[\sinh (0.0092 \sigma)]^{6.86} \cdot \exp \left(\frac{-420000}{R T}\right)$

Furthermore, considering Eqs. [4] and [5the constitutive equation of flow stress can be given as a function of Zener-Holloman parameter:

$\sigma=\frac{1}{\alpha} \sinh ^{-1}\left(\frac{Z}{A}\right)^{\frac{1}{n}}=109 \sinh ^{-1}\left(\frac{Z}{9.24 \times 10^{14}}\right)^{0.145}$ 
The activation energy and the other three material constants $(\alpha, n$ and A) were calculated at different strains in the range of 0.05-0.65, and the corresponding plots are shown in Fig. 10. Moreover, a third order polynomial equation that best fit the constants was estimated to predict the material constants at different strains.

\subsection{Prediction of stress- strain curves}

\subsubsection{Akbari et al. Model}

Generally, the stress-strain curve represents two distinct regions [22]. In region (I), the deformation of metals at high temperature illustrates a work hardening dominated stage up to the peak stress followed by region (II) which represents a monotonic decrease in stress to a steady state value. In this regards, Akbari et al. [23] have proposed a constitutive equation to solve the problems of the original Hollomon equation to predict single peak flow stress curves by incorporation of peak stress $\left(\sigma_{\mathrm{P}}\right)$ and peak strain $\left(\varepsilon_{\mathrm{P}}\right)$ as follows:

$\sigma=\sigma_{P}-B\left|\varepsilon-\varepsilon_{P}\right|^{n}$

the stress and corresponding strain data was applied before and after peak point to obtain the values of constants $B$ and $n$. Accordingly, the constants $n_{1}$ and $B_{1}$, plus $n_{2}$ and $B_{2}$ were considered before and after the peak point, respectively. Therfore, the constitutive equations were obtained for the alloy at the temperature of $1000^{\circ} \mathrm{C}$ and strain rate of $0.01 \mathrm{~s}^{-1}$ conditions as follows:

$$
\begin{array}{ll}
\text { before the peak point } & \sigma=121.42-304.25|\varepsilon-0.32|^{2.091} \\
\text { after the peak point } & \sigma=121.42-23.76|\varepsilon-0.32|^{0.78}
\end{array}
$$

The flow stress curves were calculated and compared with the experimental flow stress curves as shown in Fig. 11. This model predicts the experimetal flow stress with acceptable accuracy. However, asignificant difference is observed at low strain values. In addition, this method estimates the flow stress curves by two almost linear graphs with different slopes.

\subsubsection{Ebrahimi et al. model}

The Ebrahimi et al. model was proposed based on the phenomenological shape of single peak DRX flow stress curves. They considered the following relation for variations of strain hardening rate vs. stress and strain:

$$
\frac{d \sigma}{d \varepsilon}=C_{1}\left(\sigma-\sigma_{s s}\right)\left(1-\frac{\varepsilon}{\varepsilon_{p}}\right)
$$


where $\varepsilon_{\mathrm{P}}$ is the strain corresponding to the peak stress and $\sigma_{\mathrm{ss}}$ is the steadystate stress. The term $\left(1-\frac{\varepsilon}{\varepsilon_{P}}\right)$ estimates variation of thestress-strain curve when $\sigma>\sigma_{\mathrm{ss}}$. Solution of the differential Eq. [18] with respect to $\varepsilon$ using boundary condition $\sigma=\sigma_{\mathrm{P}}$ at $\varepsilon=\varepsilon_{\mathrm{P}}$ results in:

$$
\sigma=\sigma_{s s}+\left(\sigma_{p}-\sigma_{s s}\right) \exp \left(C_{1}\left(\varepsilon-\frac{\varepsilon_{p}}{2}-\frac{\varepsilon^{2}}{2 \varepsilon_{p}}\right)\right)
$$

where $\mathrm{C}_{1}$ can be estimated from the following expression:

$$
C_{1}=\frac{2}{\left(k^{2}-2 k+1\right) \varepsilon_{p}} \ln \left(\frac{\sigma_{p}-\sigma_{s s}}{\sigma_{C}-\sigma_{s s}}\right)
$$

Here $\varepsilon_{C}=k \varepsilon_{P}$ and $\sigma_{C}<\sigma_{s S}$.Considering the term of $\sigma_{C}>\sigma_{s s}$, the model is applicable only for deformation temperature of 1100 and $1150{ }^{\circ} \mathrm{C}$ at a strain rate of $0.01 \mathrm{~s}^{-1}$ for the alloy in this study. The comparison between the calculated flow stress curves with experimental ones is illustrated in Fig. 12. It can be seen that before the peak point the consistency between the predicted and experimental flow stress are satisfactory but after the peak the predicted flow stress is much lower than that of the exprimetal ones.

In addition, in order to prove the competency of the aforementioned models, error in prediction of flow stress curves was calculated at different deformation conditions. As shown in Fig. 13, both of the models overestimates the flow stress at very low strains when the work hardening rate is high, although the predictions using Ebrahimi et al model are a little more precise at this range of strain. This can be ascribed to the mathematical nature of the both models which predicts a low rate of approaching to the zero stress. Also, it is clear that the akbari et al. constitutive equation is more capable in prediction of flow stress curves as the average value of errors shows in table 2.

\section{Conclusions}

The dynamic recrystallization behavior of AISI 422 martensitic stainless steel has been investigated under different deformation conditions. The following principal conclusions can be drawn: 
1. The Zener-Holloman parameter during hot deformation process can be represented by $Z=\varepsilon^{\prime} \exp \left(\frac{-420000}{R T}\right)$.

2. The constitutive equation at the true strain of 0.1 describing the hot deformation can be expressed as $\varepsilon^{\cdot}=9.24 \times 10^{14}[\sinh (0.0092 \sigma)]^{8} \cdot \exp \left(\frac{-420000}{R T}\right)$.

3. The normalized critical stress for initiation of DRX was estimated to be 0.84 .

4. Akbari model was proposed a constitutive equation which can appropriately predict the flow stress curve of AISI 422 stainless steel by incorporation of the peak stress $\left(\sigma_{\mathrm{P}}\right)$ and the corresponding strain $\left(\varepsilon_{\mathrm{P}}\right)$.

5. Ebrahimi's model predicts the flow stress with a good accuracy up to peak, but after the peak point the predicted values is lower than the actual flow stress curve.

\section{References}

[1] N.V. Dashunin, E.P. Manilova and A.I. Rybnikov, Phase and structural transformations in 12\% chromium steel ÉP428 due to long-term operation of moving blades, Met. Sci. Heat Treat. 2007, 49, p 23-29.

[2] L.Y. Liberman and M.N. Sokolova, A study of forgings of full-scale rotors from stainless steel 2Kh12VNMF (ÉI802, ÉP428), Trudy TsKTI, 1965, 53, p 75-89.

[3] L.Y. Liberman, and M.I. Peisikhis, Properties of steels and alloys used for boiler and turbine production, Izd. TsKTI, Leningrad, 1966, 16, p 40-53.

[4] H. Mirzadeh, M.H. Parsa and D. Ohadi, Hot deformation behavior of austenitic stainless steel for a wide range of initial grain size, Mater. Sci. Eng. A, 2013, 569, p 54-60.

[5] L.L. Wang, R.B. Li and Y.G. Liao, Study on characterization of hot deformation of 403 steel, Mater. Sci. Eng. A, 2013, 567, p 84-88.

[6] A. Momeni and K. Dehghani, Prediction of dynamic recrystallization kinetics and grain size for 410 martensitic stainless steel during hot deformation, Met. Mat. Int., 2010, 5, p 843-849.

[7] H. Mirzadeh, J.M. Cabrera, J.M. Prado and A. Najafizadeh, Hot deformation behavior of a medium carbon microalloyed steel, Mater. Sci. Eng. A, 2011, 528, p 3876-3882.

[8] H. Mirzadeh, J.M Cabrera and A Najafizadeh, Constitutive relationships for hot deformation of austenite, Acta materi. 2011, 59, p 6441-6448.

[9] Zh. Zeng, L. Cheng, F. Zhu and X. Liu, Static recrystallization behavior of a martensitic heat-resistant stainless steel 403Nb, Acta Metall. 2011, 24 (5), p 381-389. 
[10] Zh. Zeng, L. Chen, F. Zhu and X. Liu, Dynamic Recrystallization Behavior of a Heat-resistant Martensitic Stainless Steel 403Nb during Hot Deformation, J. Mater. Sci. Technol. 27, 2011, 10, p 913919.

[11] L. Sahebdel, S.M. Abbasi and A. Momeni, Microstructural evolution through hot working of the single-phase and two-phase Ti-6Al-4V alloy, Inter. J. Mater. Resea. 2011, 102 (1), p 301-307.

[12] Y. Fang, X. Chen, B. Madigan, H. Cao and S. Konovalov, Effects of strain rate on the hot deformation behavior and dynamic recrystallization in China low activation martensitic steel, Fus. Eng. Des. 2016, 103, p 21-30.

[13] G.R. Ebrahimi, A. Momeni, M. Jahazi and P. Bocher, Dynamic recrystallization and precipitation in 13\%Cr super martensitic stainless steels, Metall. Mater. Trans. A, 2014, 45 (4), p 2219-2231.

[14] J. Huang and Z. Xu, Evolution mechanism of grain refinement based on dynamic recrystallization in multiaxially forged austenite, Mater. Let., 2006, 60 (15), p 1854-1858.

[15] A. Najafizadeh and J.J. Jonas, Predicting the Critical Stress for Initiation of Dynamic Recrystallization, ISIJ Int., 2006, 46, p 1679-1684.

[16] M. Jafari and A. Najazadeh, Comparison between the Methods of Determining the Critical Stress for Initiation of Dynamic Recrystallization in 316 Stainless Steel, J. Mater. Sci. Technol.,2008, 24 (6), p 840844.

[17] H.J. McQueen and N.D. Ryan, Constitutive analysis in hot working, Mater. Sci. Eng. A, 2002, 322, p 43-63.

[18] H. Mirzadeh and A. Najafizadeh, Flow stress prediction at hot working conditions, Mater. Sci. Eng. A, 2010, 527, p 1160-1164.

[19] M.S. Ghazani, A. Vajd and B. Mosadeg, Prediction of critical stress and strain for the onset of dynamic recrystallization in plain carbon steels, J. Mater. Sci. Eng., 2015, 12 (1), p 61-67.

[20] S.F. Medina and C.A. Hernandez, General expression of the Zener-Hollomon parameter as a function of the chemical composition of low alloy and microalloyed steels, Act. Mater., 1996, 44 (1), p $137-148$.

[21] H.J. McQueen and N.D. Ryan, Constitutive analysis in hot working, Mater. Sci. Eng. A, 2002, 322, p 43-52.

[22] R. Ebrahimi, S.H. Zahiri and A. Najafizadeh, Mathematical modelling of the stress-strain curves of Ti-IF steel at high temperature, J. Mater. Proc. Tech. 2006, 171, p 301-305.

[23] Z. Akbari, H.Mirzadeh and J.M. Cabrera, A simple constitutive model for predicting flow stress of medium carbon microalloyed steel during hot deformation, Mater. Des. 2015, 77, p 126-131. 


\section{Figure and Table Captions}

Fig.1. a) Optical and b) SEM micrographs of as forged microstructure of AISI 422 stainless steel.

Fig.2. Schematic illustration of experimental procedure of hot compression tests.

Fig.3.True stress-strain curves of AISI 422 MSS at different hot compression conditions.

Fig. 4. Optical microstructures of AISI 422 stainless steel before and after deformation at strain of 0.7: (a) without deformation; (b) deformed at $1373 \mathrm{~K}\left(1100^{\circ} \mathrm{C}\right)$ and $1 \mathrm{~s}^{-1}$; (c) deformed at 1423 $\mathrm{K}\left(1150^{\circ} \mathrm{C}\right)$ and $0.1 \mathrm{~s}^{-1} ;(\mathrm{d})$ deformed at $1373 \mathrm{~K}\left(1100^{\circ} \mathrm{C}\right)$ and $0.1 \mathrm{~s}^{-1}$.

Fig. 5. Grain size distribution curve of as forged specimen with an average grain size of about ASTM 5.5.

Fig. 6. $\mathrm{d} \theta / \mathrm{d} \sigma$ versus $\sigma$ curve at temperature of $1423 \mathrm{~K}\left(1150^{\circ} \mathrm{C}\right)$ and strain rate of $0.1 \mathrm{~s}^{-1}$, the minimum point representing the critical stress for DRX.

Fig. 7.The relationship between critical and peak stress at different temperatures and strain rates. Fig. 8. Evaluation of the value (a) $n_{1}$ by plotting $\ln \sigma$ versus $\ln \varepsilon^{\circ}$, (b) $\beta$ by plotting $\sigma$ versus $\ln \varepsilon^{\circ}$, (c) $n$ by plotting $\ln [\sinh (\alpha \sigma)]$ versus $\ln \varepsilon^{\circ}$, (d) Q by plotting $\ln [\sinh (\alpha \sigma)]$ versus $1 / \mathrm{T}$.

Fig. 9. relationship between $\ln Z$ versus. $\ln [\sinh (\alpha \sigma)]$

Fig. 10. Relationship between (a) $\alpha$, (b) n,(c) Q, (d) $\ln A$ and true strain.

Fig. 11. Comparison between the experimental and the calculated flow curves (solid lines) by the Akbari's model (dash lines) at (a) $950^{\circ} \mathrm{C}$, (b) $1000^{\circ} \mathrm{C}$, (c) $1050{ }^{\circ} \mathrm{C}$, (d) $1100{ }^{\circ} \mathrm{C}$, (e) $1150{ }^{\circ} \mathrm{C}$ and different strain rates.

Fig. 12. Comparison between the experimental and the calculated flow curves by the Ebrahimi's model at 1100 and $1150{ }^{\circ} \mathrm{C}$ and $0.01 \mathrm{~s}-1$ strain rate.

Fig.13. percent error for Akbari and Ebrahimi model in comparison with exprimental results.

Table 1. Chemical composition of AISI 422 martensitic stainless steel.

Table 2. The percent error for the modeling techniques used in this study. 


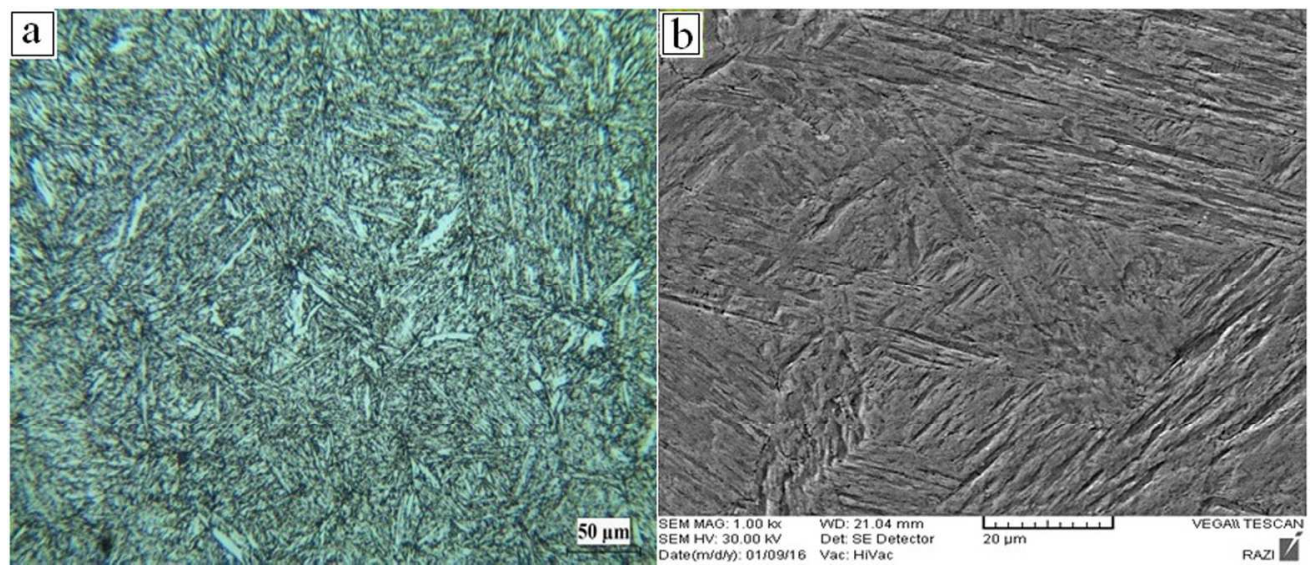

Fig.1. a) Optical and b) SEM micrographs of as forged microstructure of AISI 422 stainless steel. $189 \times 81 \mathrm{~mm}(300 \times 300 \mathrm{DPI})$ 


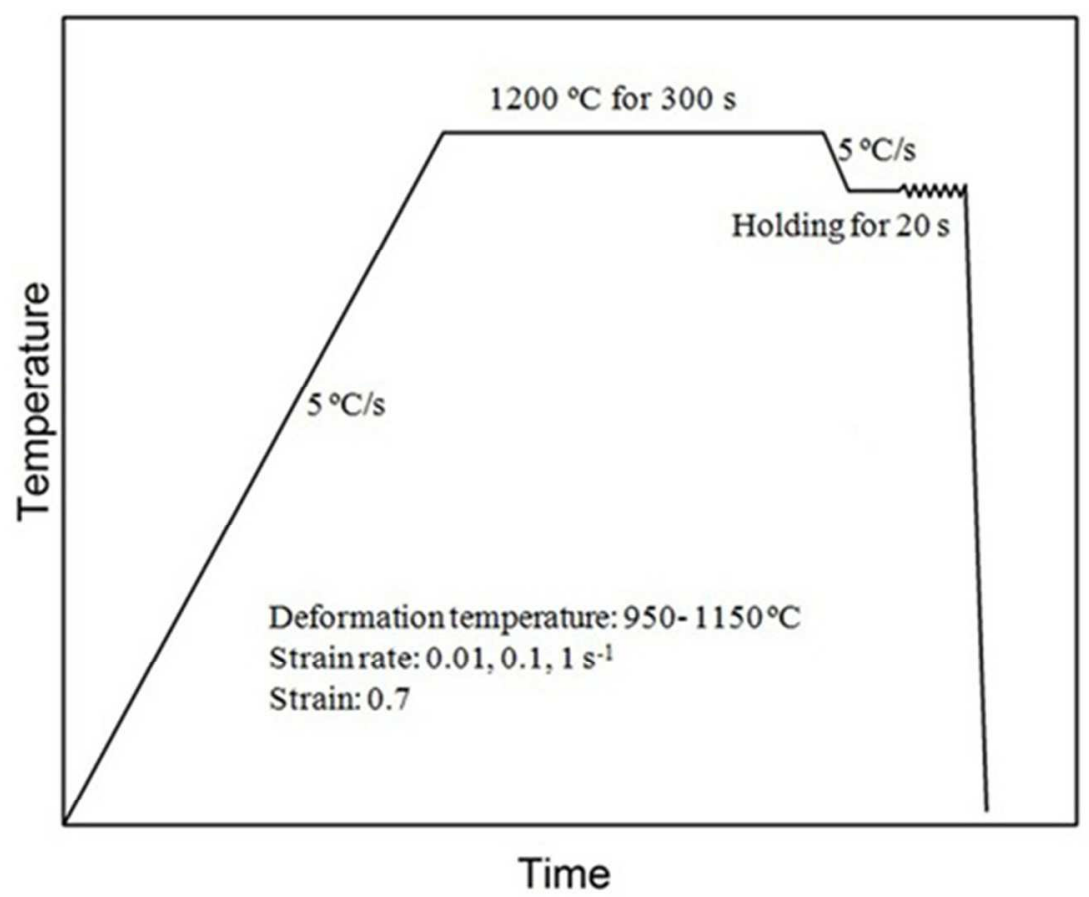

Fig.2. Schematic illustration of experimental procedure of hot compression tests.

$152 \times 112 \mathrm{~mm}(300 \times 300 \mathrm{DPI})$ 

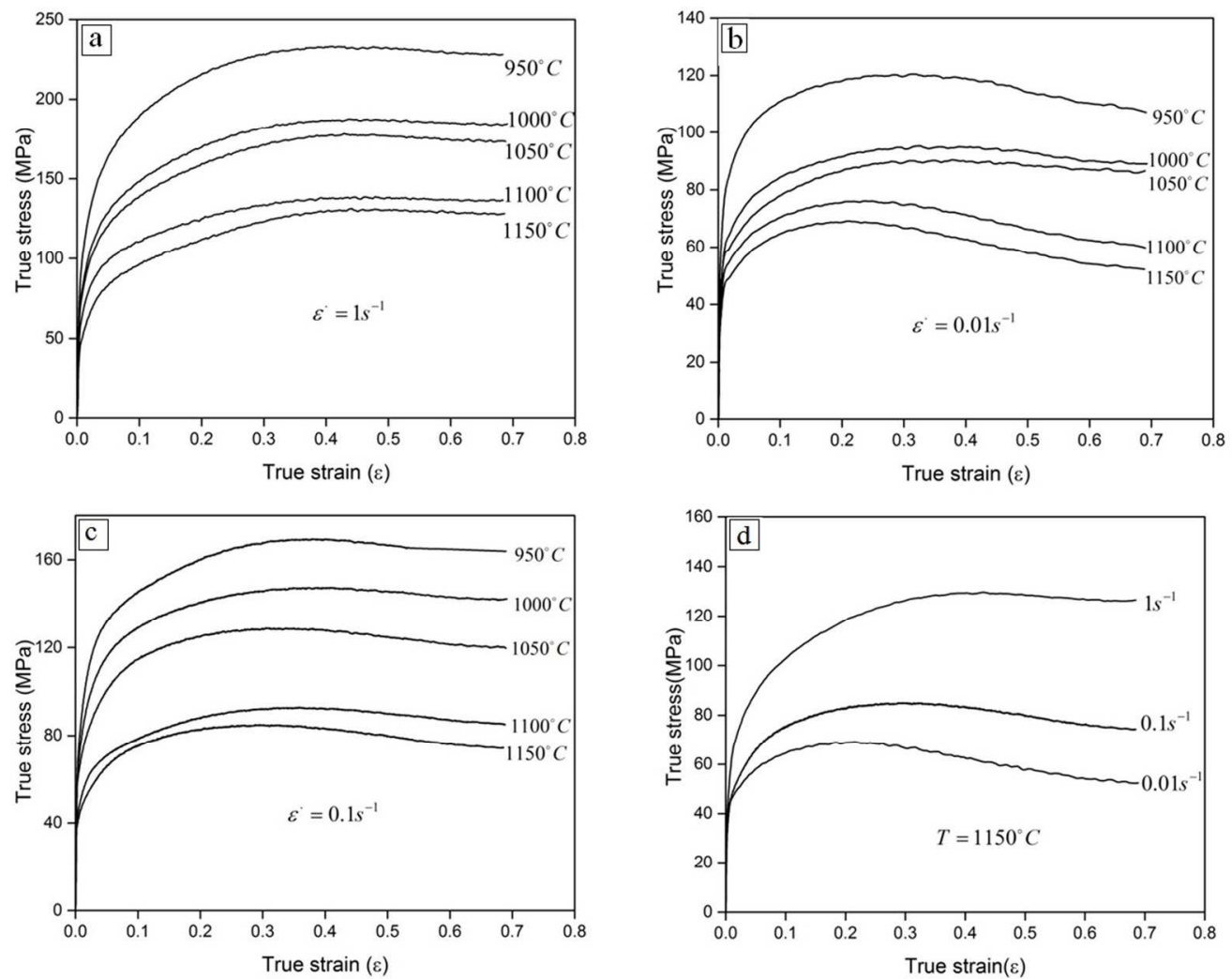

Fig.3.True stress-strain curves of AISI 422 MSS at different hot compression conditions. $189 \times 152 \mathrm{~mm}(300 \times 300 \mathrm{DPI})$ 

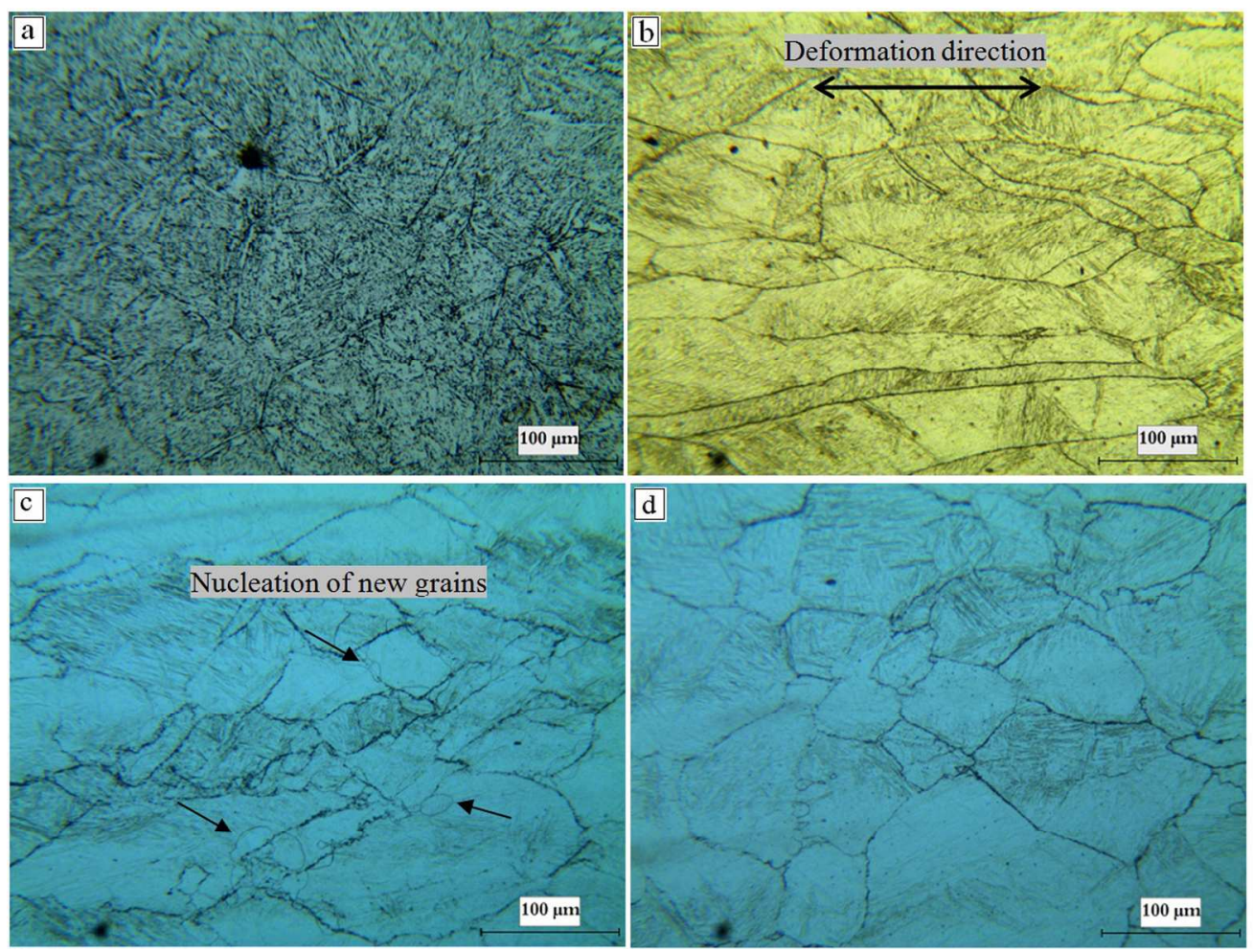

Fig. 4. Optical microstructures of AISI 422 stainless steel before and after deformation at strain of 0.7: (a) without deformation; (b) deformed at $1373 \mathrm{~K}\left(1100^{\circ} \mathrm{C}\right)$ and $1 \mathrm{~s}-1$; (c) deformed at $1423 \mathrm{~K}\left(1150^{\circ} \mathrm{C}\right)$ and 0.1 $\mathrm{s}-1 ;(\mathrm{d})$ deformed at $1373 \mathrm{~K}\left(1100{ }^{\circ} \mathrm{C}\right)$ and $0.1 \mathrm{~s}-1$

$189 \times 143 \mathrm{~mm}(300 \times 300 \mathrm{DPI})$ 


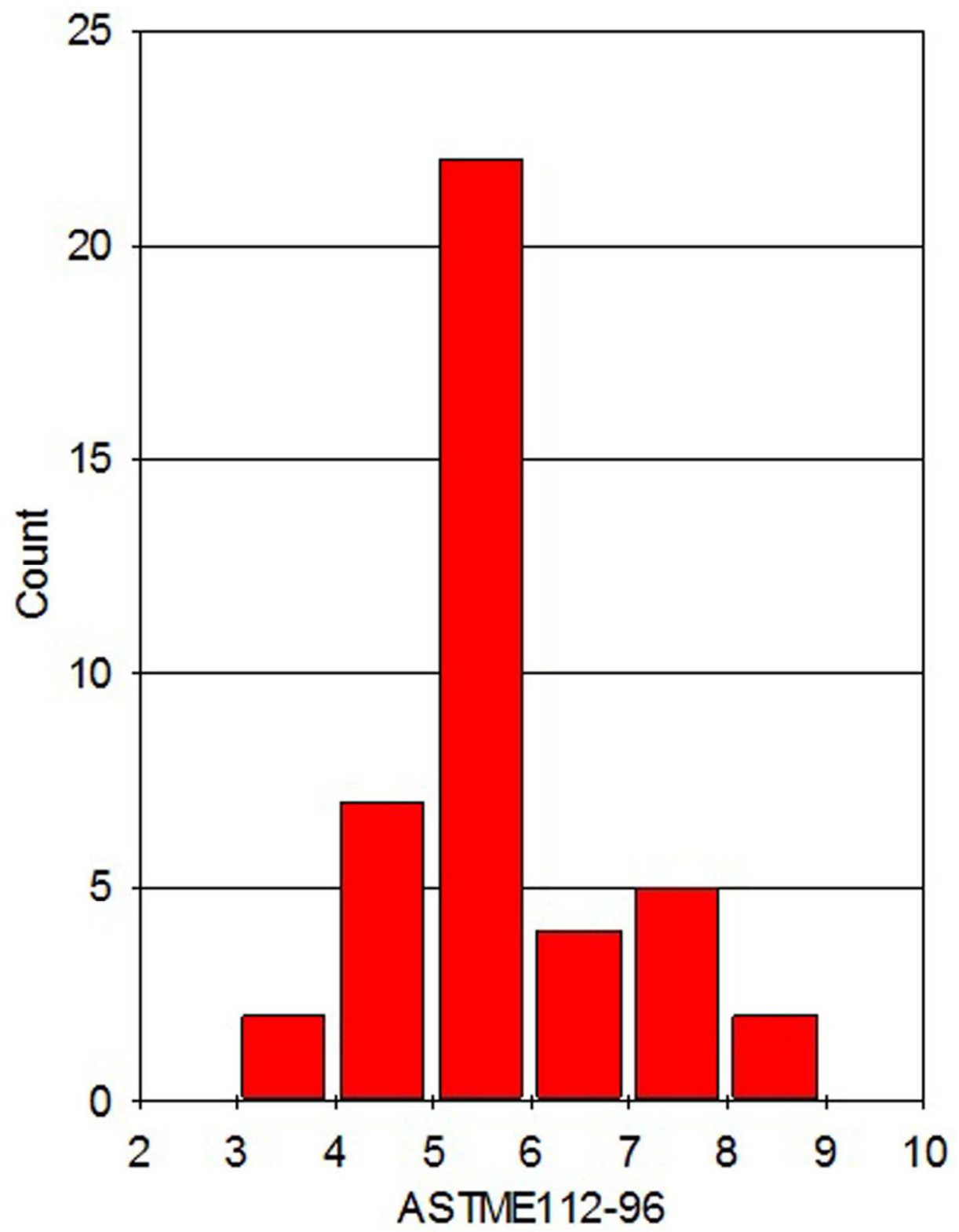

Fig. 5. Grain size distribution curve of as forged specimen with an average grain size of about ASTM 5.5. $90 \times 116 \mathrm{~mm}(300 \times 300 \mathrm{DPI})$ 


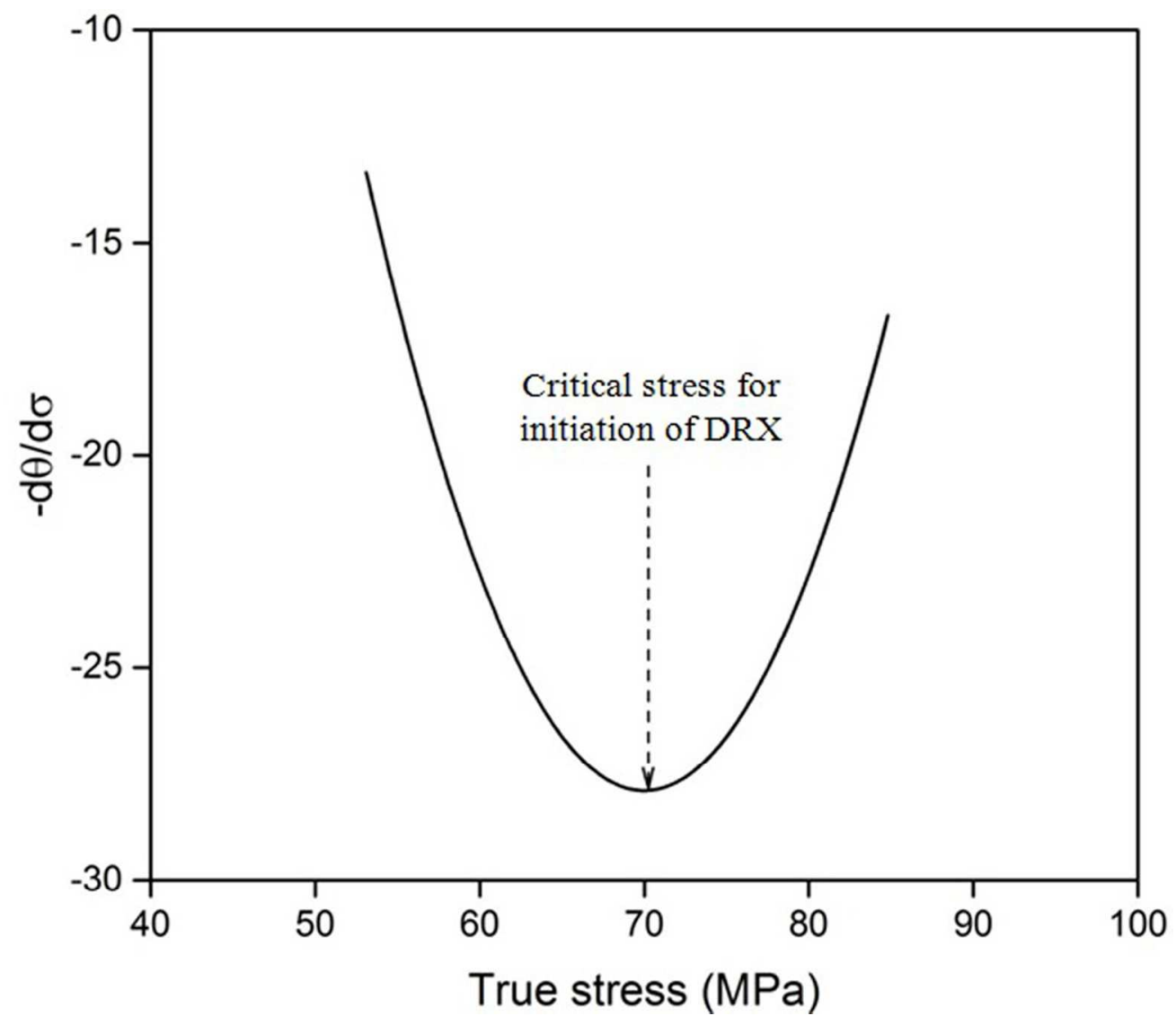

Fig. 6. $\mathrm{d} \theta / \mathrm{d} \sigma$ versus $\sigma$ curve at temperature of $1423 \mathrm{~K}\left(1150^{\circ} \mathrm{C}\right)$ and strain rate of $0.1 \mathrm{~s}-1$, the minimum point representing the critical stress for DRX.

$90 \times 77 \mathrm{~mm}(300 \times 300 \mathrm{DPI})$ 


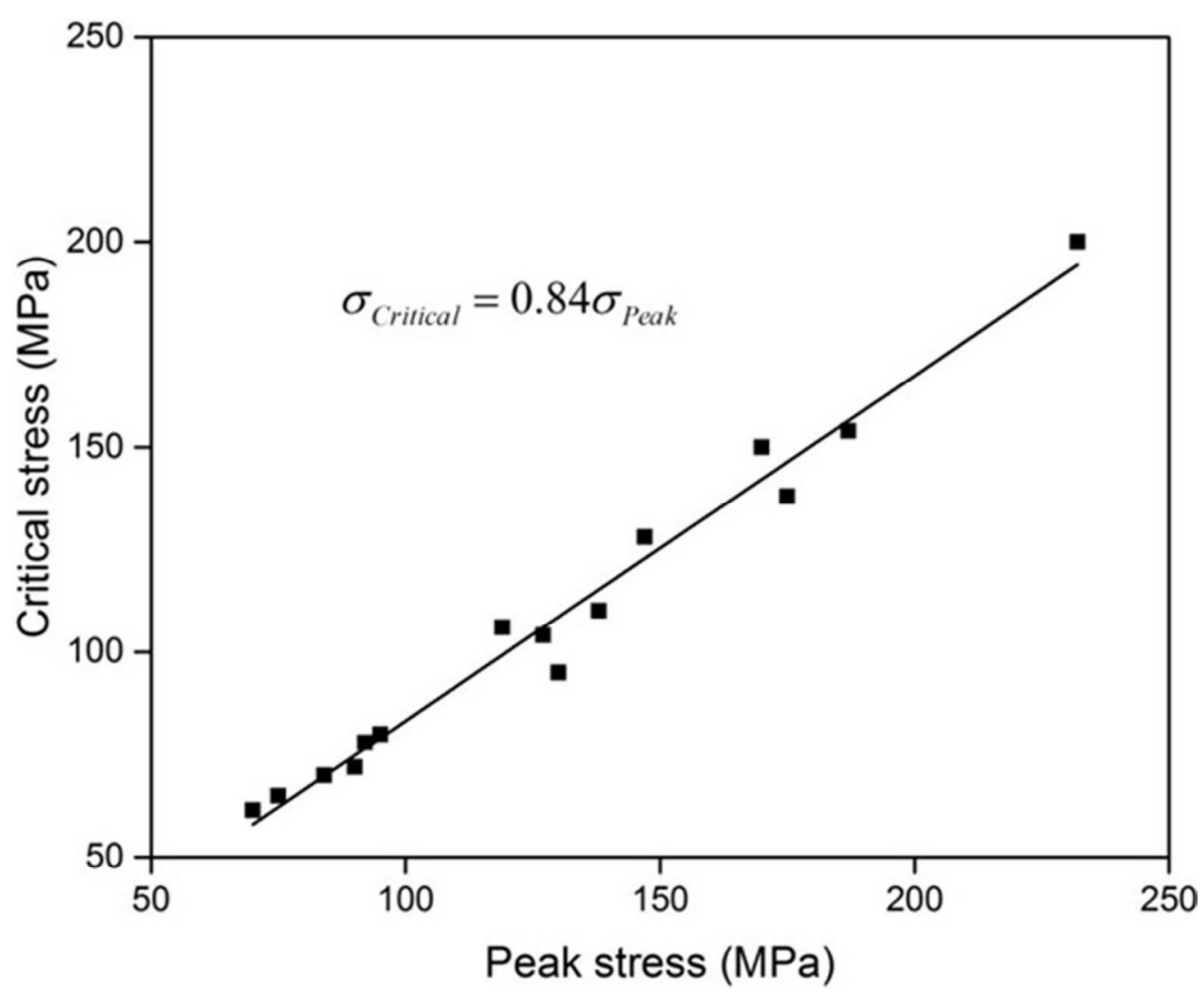

Fig. 7.The relationship between critical and peak stress at different temperatures and strain rates. $90 \times 73 \mathrm{~mm}(300 \times 300 \mathrm{DPI})$ 

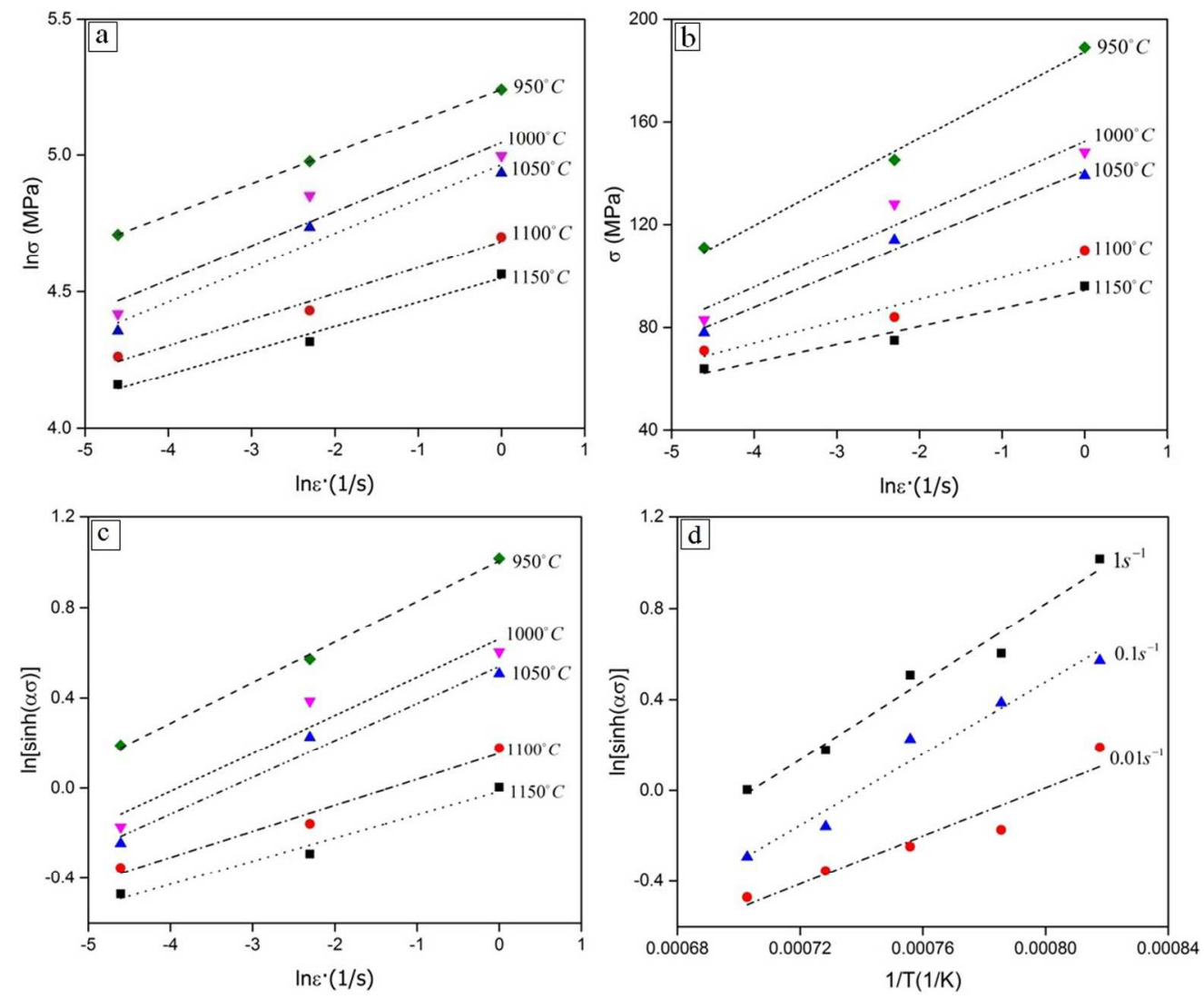

Fig. 8. Evaluation of the value (a) $n 1$ by plotting $\ln \sigma$ versus $\ln \varepsilon^{\circ}$, (b) $\beta$ by plotting $\sigma$ versus $\ln \varepsilon^{\circ}$, (c) $n$ by plotting $\ln [\sinh (a \sigma)]$ versus $\ln \varepsilon^{\circ}$, (d) $Q$ by plotting $\ln [\sinh (a \sigma)]$ versus $1 / T$.

$189 \times 158 \mathrm{~mm}(300 \times 300 \mathrm{DPI})$ 
1

2

3

4

5

6

7

8

9

10

11

12

13

14

15

16

17

18

19

20

21

22

23

24

25

26

27

28

29

30

31

32

33

34

35

36

37

38

39

40

41

42

43

44

45

46

47

48

49

50

51

52

53

54

55

56

57

58

59

60

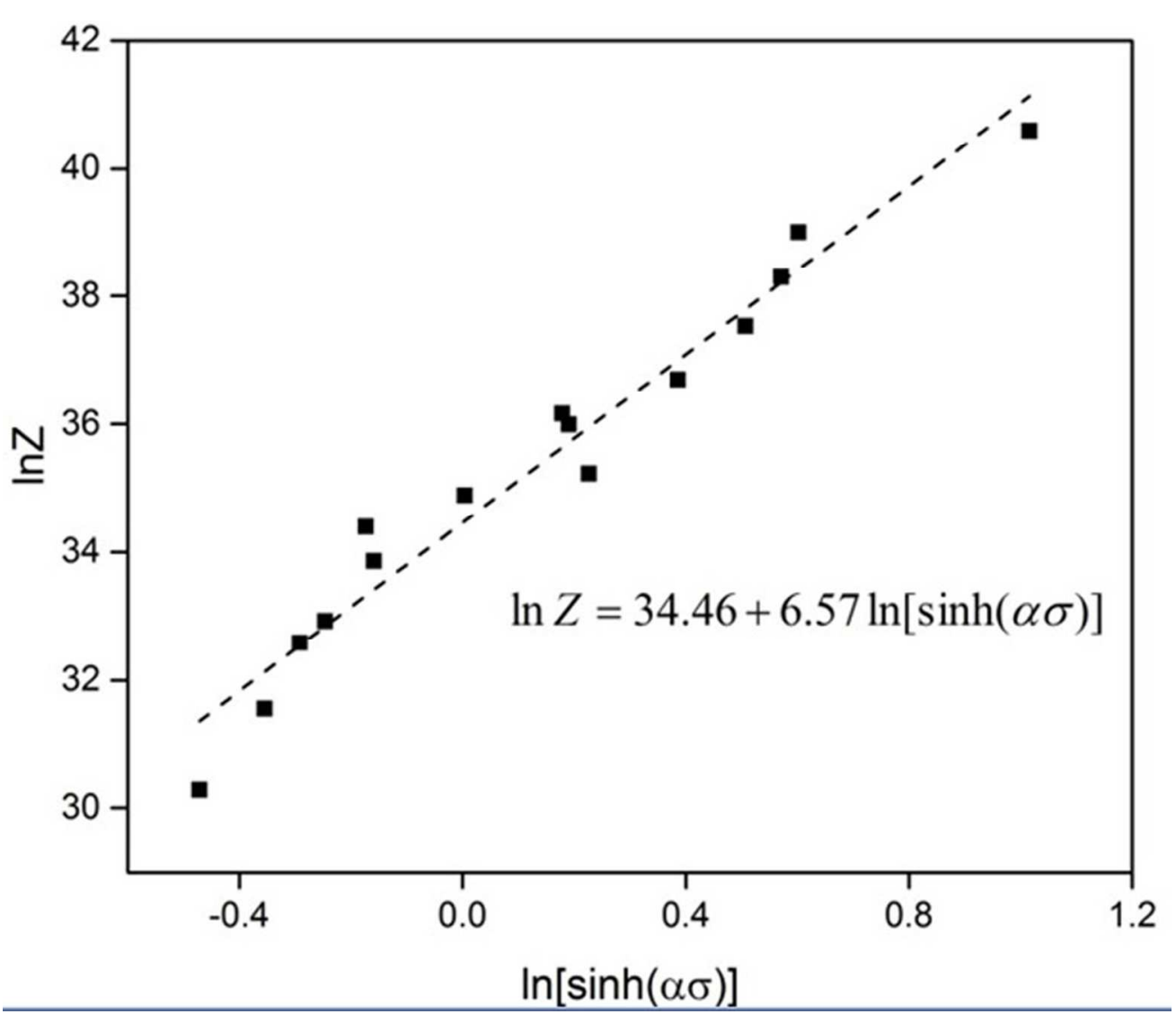

Fig. 9. relationship between $\ln Z$ versus. In $[\sinh (a \sigma)]$ $90 \times 76 \mathrm{~mm}(300 \times 300$ DPI $)$ 

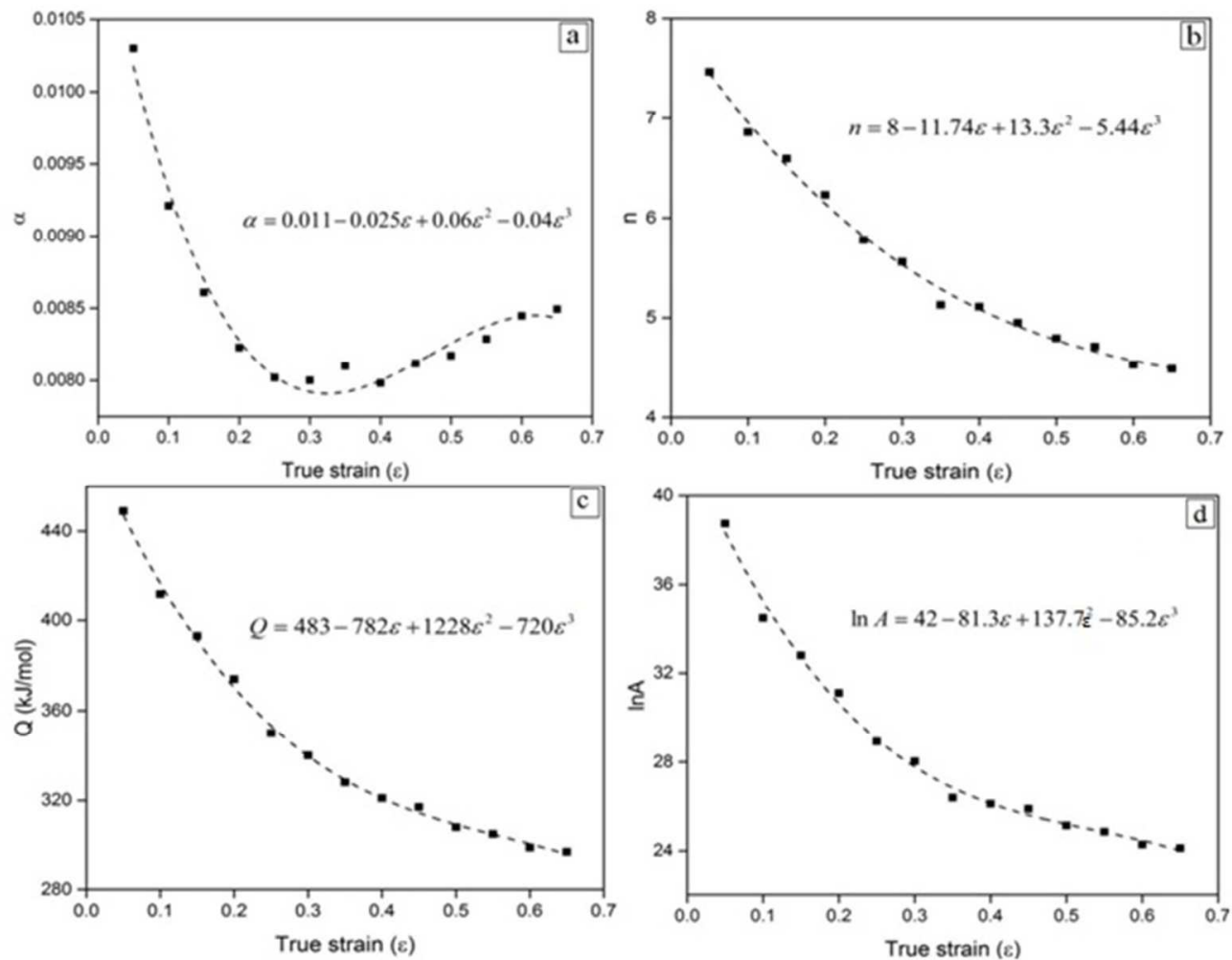

Fig. 10. Relationship between (a) $a,(b) n_{,}(c) Q_{r}$ (d) InA and true strain. $167 \times 133 \mathrm{~mm}(300 \times 300$ DPI $)$ 

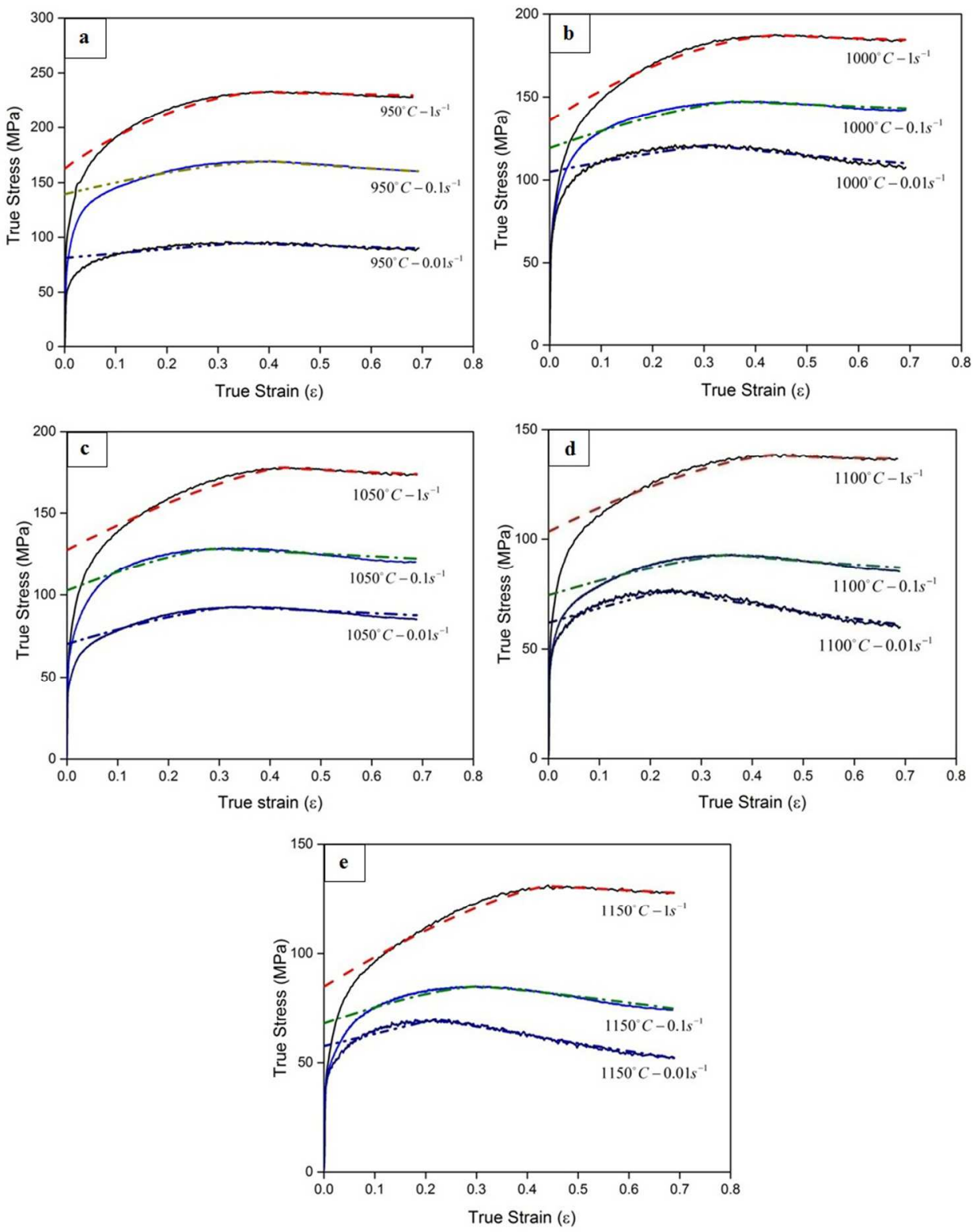

Fig. 11. Comparison between the experimental and the calculated flow curves (solid lines) by the Akbari's model (dash lines) at (a) $950^{\circ} \mathrm{C}$, (b) $1000^{\circ} \mathrm{C}$, (c) $1050{ }^{\circ} \mathrm{C}$, (d) $1100^{\circ} \mathrm{C},(\mathrm{e}) 1150{ }^{\circ} \mathrm{C}$ and different strain rates. 


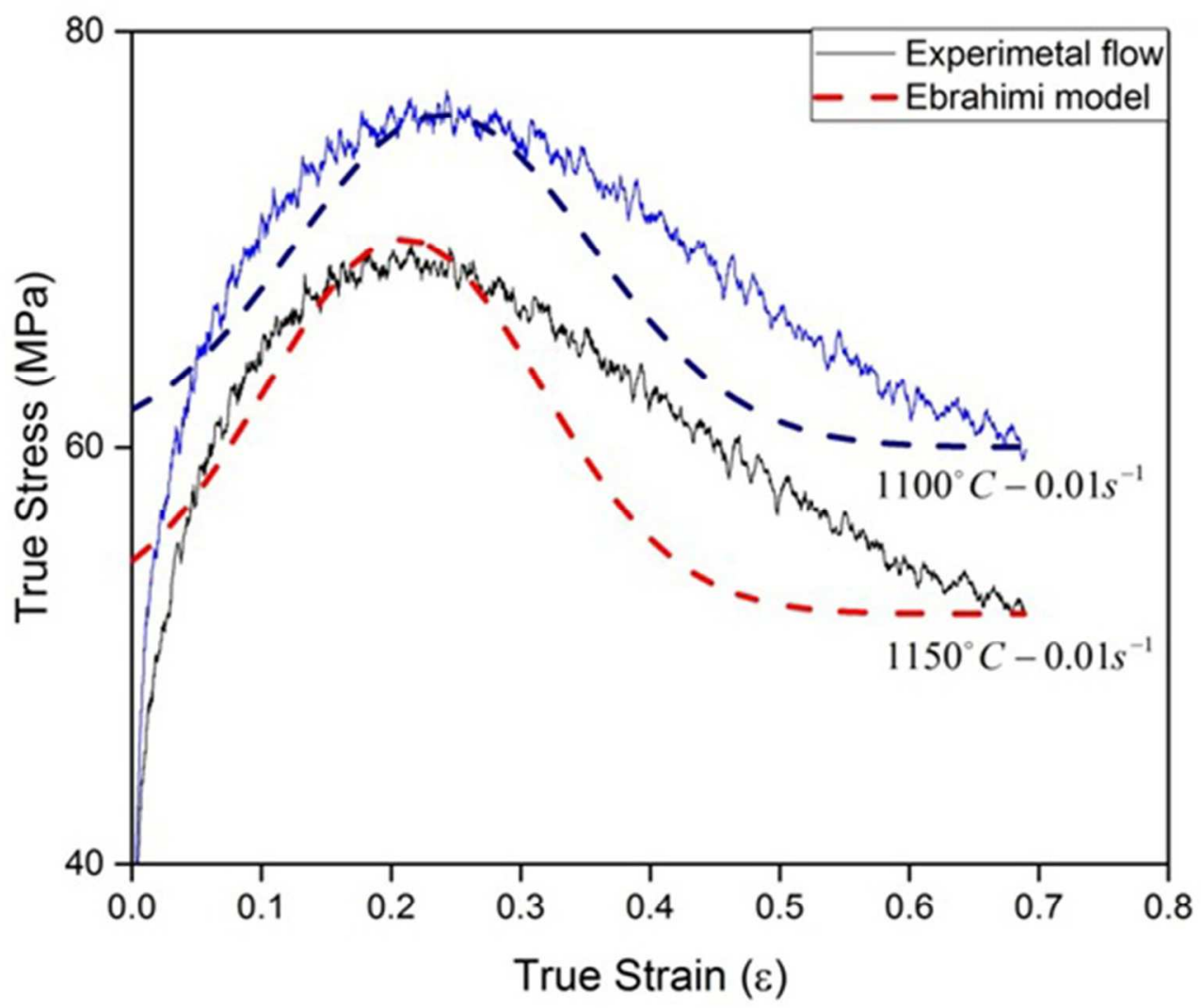

Fig. 12. Comparison between the experimental and the calculated flow curves by the Ebrahimi's model at 1100 and $1150{ }^{\circ} \mathrm{C}$ and $0.01 \mathrm{~s}-1$ strain rate. 
1

2

3

4

5

6

7

8

9

10

11

12

13

14

15

16

17

18

19

20

21

22

23

24

25

26

27

28

29

30

31

32

33

34

35

36

37

38

39

40

41

42

43

44

45

46

47

48

49

50

51

52

53

54

55

56

57

58

59

60

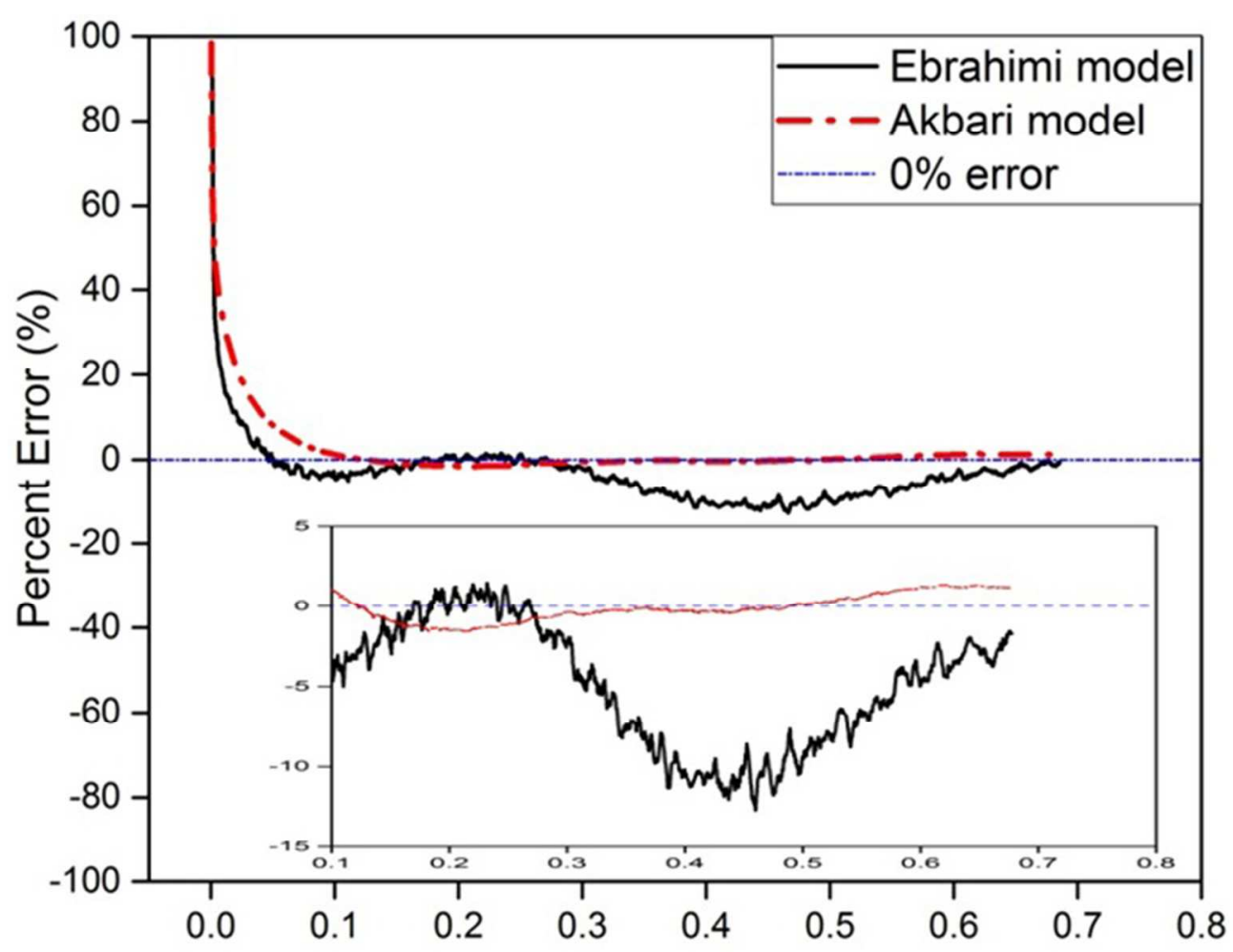

Fig.13. percent error for Akbari and Ebrahimi model in comparison with exeprimental results.

$183 \times 139 \mathrm{~mm}(300 \times 300 \mathrm{DPI})$ 
Table 1. Chemical composition of AISI 422 martensitic stainless steel.

\begin{tabular}{|c|c|c|c|c|c|c|c|c|c|c|}
\hline Element & $\mathrm{C}$ & $\mathrm{Si}$ & $\mathrm{Mn}$ & $\mathrm{P}$ & $\mathrm{S}$ & $\mathrm{Cr}$ & $\mathrm{Mo}$ & $\mathrm{Ni}$ & $\mathrm{W}$ & $\mathrm{Fe}$ \\
\hline Wt. $\%$ & 0.21 & 0.29 & 0.62 & 0.017 & 0.006 & 12.02 & 0.96 & 0.90 & 1.02 & Bal. \\
\hline
\end{tabular}


1

2

3

4

5

6

7

8

9

10

11

12

13

14

15

16

17

18

19

20

21

22

23

24

25

26

27

28

29

30

31

32

33

34

35

36

37

38

39

40

41

42

43

44

45

46

47

48

49

50

51

52

53

54

55

56

57

58

59

60

Table 2. The percent error for the modeling techniques used in this study.

\begin{tabular}{|c|c|c|c|c|}
\hline \multirow{2}{*}{ Method } & \multicolumn{2}{|c|}{$\varepsilon<0.1$} & \multicolumn{2}{c|}{$\varepsilon>0.1$} \\
\cline { 2 - 5 } & Ebrahimi & Akbari & Ebrahimi & Akbari \\
\hline \% error & 12.49 & 18.32 & 4.92 & 0.68 \\
\hline
\end{tabular}

